\title{
Anti-A and Anti-B Haemolysins amongst Group “O” Voluntary Blood Donors in Northeastern Nigeria
}

\author{
M. B. Kagu, ${ }^{1,2}$ Sagir G. Ahmed, ${ }^{2}$ Aisha A. Mohammed, ${ }^{3}$ Waheed K. Moshood, ${ }^{1}$ \\ Mohammed B. Malah, ${ }^{2}$ and Jimoh M. Kehinde ${ }^{2}$ \\ ${ }^{1}$ North-East Zonal Centre, National Blood Transfusion Service, Maiduguri, Nigeria \\ ${ }^{2}$ Department of Haematology \& Blood Transfusion, University of Maiduguri Teaching Hospital, P.M.B.1414 Maiduguri, \\ Borno State, Nigeria \\ ${ }^{3}$ Department of Haematology \& Blood Transfusion, Aminu Kano Teaching Hospital, P.M.Bc 3452 Kano, Nigeria
}

Correspondence should be addressed to M. B. Kagu, bmk449@yahoo.com

Received 30 June 2010; Accepted 26 September 2010

Academic Editor: Mike Murphy

Copyright (๑) 2011 M. B. Kagu et al. This is an open access article distributed under the Creative Commons Attribution License, which permits unrestricted use, distribution, and reproduction in any medium, provided the original work is properly cited.

\begin{abstract}
Background and Objective. The aim of this study was to determine the prevalence and haemolytic significance of alpha- and betahaemolysins in our voluntary group "O" donor population. Methods. This was a prospective study carried out at North-East Zonal Centre, the National Blood Transfusion Service, Maiduguri, Nigeria from April 2007 to April 2009. One thousand nine hundred and twenty nine voluntary group "O" blood donors (1609 males and 320 females, median age 26 years $\pm 7.6 \mathrm{SD}$ ) were screened for alpha- (anti-A) and beta- (anti-B) haemolysins using the standard tube technique at 37 degrees $\mathrm{C}$ for 1 hour. All samples showing haemolysis were titrated for anti-A and anti-B haemolysins. Results. The overall prevalence of haemolysins in group $\mathrm{O}$ donors was $55.4 \%$. Prevalence of alpha- and beta-haemolysins only was $10.3 \%$ and $12.6 \%$, respectively, while that of donors having both alpha- and beta-haemolysins in their sera was $32.5 \%$. Visual titre of 8 was seen in $0.4 \%$ of lytic alpha-haemolysin and $0.2 \%$ of lytic beta-haemolysin whereas donors with both alpha- and beta-haemolysins had a titre of $1.8 \%$. Lytic titre of 16 and 32 was very low in our donor population. Conclusion. This study has shown that although the prevalence of haemolysins is high in our voluntary group "O" donor population, the strength of the lytic antibodies is low. Therefore, despite the labour intensiveness of our haemolysis titration technique and the frequent transfusion of group O blood to certain recipients of blood group A, B, and $\mathrm{AB}$ in our environments, there is the need to routinely screen our donors for haemolysins in order to identify those posing the greatest risk to recipients. Further studies to determine episodes of clinically significant haemolysis in recipients of blood group $\mathrm{O}$ may be necessary.
\end{abstract}

\section{Introduction}

The importance of a blood group system in clinical blood transfusion practice lies in the frequency of its antibodies and in the possibility that such antibodies will destroy incompatible cells in vivo [1]. Almost everybody over the age of 6 months has clinically significant anti-A and/or anti$\mathrm{B}$ in their serum if they lack the corresponding antigens on their red cells [1]. Blood group "O" red cells can be given to $\mathrm{A}, \mathrm{B}$, or $\mathrm{AB}$ recipients and were formerly inappropriately called "Universal donor red cells". Early studies from Nigeria have shown high frequency of potentially lytic anti-A and lytic anti-B in blood group "O" persons $[2,3]$. These high frequency of alpha- and beta-haemolysins has been suggested to be responsible for the high frequency of ABO-haemolytic disease of the newborn seen in Africans [4,5]. Blood group "O" is the commonest and most prescribed blood group type in our environment [6]. The fractionation of blood into its various components is still a nightmare in Nigerian blood transfusion service centres and the hospital blood banks. Apathy to blood donation coupled with poor funding is mostly responsible for these difficulties. As such most clinicians often transfused group compatible whole blood to recipients who ordinarily need packed red cells and/or fresh plasma. The occurrence of anti-A (alpha-haemolysin) and anti-B (beta-haemolysin) in group "O" donors was reported 
TABLE 1: Distribution pattern of haemolysins among the group "O" donors.

\begin{tabular}{|c|c|c|c|c|c|}
\hline Gender & Anti-A & Anti-B & Anti-A+B & $\begin{array}{l}\text { Negative for } \\
\text { haemolysins }\end{array}$ & Total (\%) \\
\hline Male & $159(8.2)$ & $220(11.4)$ & $528(27.4)$ & $702(36.4)$ & $1609(83.4)$ \\
\hline Female & $40(2.1)$ & $24(1.2)$ & $98(5.1)$ & $158(8.2)$ & $320(16.6)$ \\
\hline Total & $199(10.3)$ & $244(12.6)$ & $626(32.5)$ & $860(44.6)$ & $1929(100)$ \\
\hline
\end{tabular}

TAble 2: Visual titres of anti-A, anti-B, and anti-A+B among the group "O" donors.

\begin{tabular}{lcccc}
\hline Titre & Anti-A & Anti-B & Anti- A+B & Total $(\%)$ \\
\hline 1 & $33(3.0)$ & $34(3.2)$ & $87(8.1)$ & $154(14.3)$ \\
2 & $106(9.9)$ & $127(11.9)$ & $336(31.4)$ & $569(53.2)$ \\
4 & $53(5.0)$ & $78(7.3)$ & $179(16.7)$ & $310(29.0)$ \\
8 & $4(0.4)$ & $2(0.2)$ & $19(1.8)$ & $25(2.4)$ \\
16 & $2(0.2)$ & $1(0.1)$ & $4(0.4)$ & $7(0.7)$ \\
32 & $1(0.1)$ & $2(0.2)$ & $1(0.1)$ & $4(0.4)$ \\
\hline Total & 199 & 244 & 626 & $1069(100.0)$ \\
\hline
\end{tabular}

to be high in African population [7-9], and as such, some laboratories still spend a great deal of time screening for these lytic haemolysins using the labour-intensive technique due to the nonavailability of automated technique. The prevalence of these haemolysins also varies with age and gender $[8,9]$.

No similar study was carried out in this part of the country to investigate the prevalence and the strength of alpha- and beta-haemolysins in our voluntary group "O" donor population, hence the necessity of this study.

\section{Materials and Methods}

2.1. Materials. Blood samples for the study were obtained from voluntary group "O" donors, who had been screened, found fit, and accepted as donors. About $4 \mathrm{mls}$ of haemoglobin-free serum was obtained from clotted samples, and these were stored at minus $18-20^{\circ} \mathrm{C}$ until they were analyzed (all samples were tested within 12 hours of separation after addition of absorbed fresh $\mathrm{O}$ serum as a source of complement). Although the lytic property of serum deteriorates rapidly on storage due to decay of complements, storage is to avoid the effect of high temperature in our environment that would also affect the potency of antibodies [10].

2.2. Methods. One volume of donor serum and one volume of absorbed fresh $\mathrm{O}$ serum (as a source of complement because the lytic property of serum deteriorates rapidly on storage due to decay of complements) were placed into each of 3 test tubes. To each tube was added 1 volume of $5 \%$ suspension in saline solution of red cells of group A, B, and 0 , respectively. The $\mathrm{O}$ cells were used as negative control. The tubes were then incubated at $37^{\circ} \mathrm{C}$ for 1 hour, after which all tubes were centrifuged. They were then held before a source of light, and with minimal disturbances, the supernatant was examined for haemolysis microscopically. Haemolysis was graded as follows: $3+$ : complete haemolysis, $2+$ : partial (more than $50 \%$ but not complete) haemolysis, 1+: trace haemolysis, and negative, no visual visible haemolysis. All samples showing haemolysis were titrated for anti-A and anti-B haemolysins as follows: $2 \mathrm{mls}$ of each serum was double diluted serially in saline up to 256 and $0.5 \mathrm{mls}$ of each serum dilution and $0.5 \mathrm{mls}$ of absorbed fresh group $\mathrm{O}$ serum were placed in each of 3 tubes. To each tube was than added $0.5 \mathrm{mls}$ of $5 \%$ A-cells, B-cells, and Ocells, respectively and the mixture was incubated at $37^{\circ} \mathrm{C}$. At 1 hour, the samples were examined for haemolysis microscopically, and the titres were recorded. Titres were recorded as the dilution showing the weakest haemolysis microscopically. All data were analysed by standard statistical software (SPSS, Chicago, IL, USA). A $P$ value of $<.05$ was considered significant.

\section{Results}

One thousand nine hundred and twenty nine sera from voluntary group "O" donors (1855-Rhesus D Positive and 74 Rhesus D Negative) were examined by the method described for anti-A and anti-B haemolysins. The median age of the donors was 26 years +7.6SD. These included 1609 males and 320 females. The overall prevalence of haemolysins in group $\mathrm{O}$ donors was 55.4\%. Alpha- and beta-haemolysins only was seen in $10.3 \%$ and $12.6 \%$ of the donors, respectively, while that of donors having both alphaand beta-haemolysins in their sera was 32.5\% (Table 1). Visual titre of 8 was seen in $0.4 \%$ of lytic alpha-haemolysin and $0.2 \%$ of lytic beta-haemolysin whereas donors with both alpha- and beta-haemolysins had a titre of $1.8 \%$ (Table 2). Lytic titre of 16 and 32 was very low (Table 2). There was no statistically significant difference between male and female donors in the frequency of haemolysins. Age also has no significant impact on the frequency of haemolysins in this study.

\section{Discussion}

This study has confirmed the high frequency of haemolysins in Nigerian group "O" donors. The prevalence of $55.4 \%$ observed in this study is higher than those reported by Olawumi and Olatunji in Ilorin (Southwestern Nigeria) [8] in 2001, Worlledge et al. (Southsouthern Nigeria) [3] in 1974, and Kulkarni et al. in Zaria (Northwestern Nigeria) [2] in 1985 as well as the work reported by Onwukeme and Nanna in Jos (North-central Nigeria) [11] in 1990. The higher prevalence rate observed in this study could be 
due to the methods and the fact that large population of group "O" donors were screened. Another possible reason could be the geographical location of Maiduguri bordering the Republic of Cameroun to the south, the Republic of Niger to the North, and the Republic of Tchad to the east. Admixture of blood of immigrants as a result of intermarriages could also be responsible for the higher prevalence. This geographical variation in the prevalence has been described in the literature $[2,11]$. There was no statistically significant difference between male and female donors in the frequency of haemolysins. This is in conformity with the work reported by other workers $[8,10]$. There was also no significant age difference in the prevalence of haemolysins. This is consistent with the findings of other workers $[8,12]$. Although episodes of haemolysis in the recipients were not determined in this study so as to justify the clinical significance of such antibodies, it will be an overstatement to state that the frequency of strongly lytic anti-A and anti-B is low in this study. Taking a visual titre of 8 and above as being able to cause significant in vivo haemolysis [13], only $0.4 \%$ of the sera positive for alphahaemolysin and $0.2 \%$ of those positive for beta-haemolysin had significant visual titre of 8 . Similarly, a titre of 16 was seen in only $0.2 \%$ for haemolytic anti-A and $0.1 \%$ for haemolytic anti-B. This finding is lower than that reported by Olawumi and Olatunji [8] who found a significant prevalence titre of $2.0 \%$ for anti-A and $2.8 \%$ for anti-B. The difference could be due to the methods and the large sample size used in this study. In a study of the distribution of antiA haemolysins in group "O" donors, David-West [14] found most titres to be not more than 16. In this study, most titres are between 2 and 4 . This study has shown that although the prevalence of haemolysins is high in our voluntary group "O" donor population, the strength of the lytic antibodies is low. Therefore, despite the labour intensiveness of our haemolysis titration technique and the frequent transfusion of group $\mathrm{O}$ blood to certain recipients of blood group $\mathrm{A}, \mathrm{B}$, and $\mathrm{AB}$ in our environments, there is the need to routinely screen our donors for haemolysins in order to identify those posing the greatest risk to recipients. A further study to determine the episodes of haemolysis in the recipients of blood group $\mathrm{O}$ is needed so as to justify the clinical significance of such antibodies.

\section{Acknowledgment}

The authors would like to acknowledge the contributions of all the staff of the National Blood Transfusion Service, Northeast Zonal Centre, Maiduguri, Nigeria.

\section{References}

[1] C. Marcela and L. Antole, "Antigens in human blood," in Postgraduate Haematology, chapter 10, pp. 186-189, ButterworthHeinemann, Boston, Mass, USA, 4th edition, 1999.

[2] A. G. Kulkarni, R. Ibazebe, and A. F. Fleming, "High frequency of anti-A and anti-B haemolysins in certain ethnic groups of Nigeria," Vox Sanguinis, vol. 48, no. 1, pp. 39-41, 1985.
[3] S. Worlledge, S. E. Ogiemudia, and C. O. Thomas, "Blood group antigens and antibodies in Nigeria," Annals of Tropical Medicine and Parasitology, vol. 68, no. 3, pp. 249-264, 1974.

[4] C. Chintu, A. Zipursky, and M. Blajchman, "ABO haemolytic disease of the newborn," East African Medical Journal, vol. 56, no. 7, pp. 314-319, 1979.

[5] H. N. Kirkman Jr., "Further evidence for a racial difference in frequency of $\mathrm{ABO}$ hemolytic disease," Journal of Pediatrics, vol. 90, no. 5, pp. 717-721, 1977.

[6] M. B. Kagu, S. G. Ahmed, and B. H. Askira, "Utilization of blood transfusion service in north eastern Nigeria," Highland Medical Research Journal, vol. 5, no. 2, pp. 27-30, 2007.

[7] L. A. Okafor and S. Enebe, "Anti-A and anti-B haemolysins, dangerous universal blood donors and the risk of $\mathrm{ABO}$ antagonism in a Nigerian community," Tropical and Geographical Medicine, vol. 37, no. 3, pp. 270-272, 1985.

[8] H. O. Olawumi and P. O. Olatunji, "Prevalence and titre of alpha and beta haemolysins in blood group 'O' donors in Ilorin," African Journal of Medicine and Medical Sciences, vol. 30, no. 4, pp. 319-321, 2001.

[9] A. O. Emeribe, "The status of alpha and beta haemolysins in Nigerian blood donors," East African Medical Journal, vol. 67, no. 3, pp. 205-208, 1990.

[10] H. G. Klein and D. J. Anstee, "Blood grouping techniques," in Mollison's Blood Transfusion in Clinical Medicine, pp. 302-310, Blackwell Scientific Publications, Oxford, UK, 11th edition, 2005.

[11] K. E. Onwukeme and O. U. Nanna, "Frequency of anti-A and anti-B haemolysins in Nigerians living in Jos," The Nigerian Medical Practitioner, vol. 20, p. 29, 1990.

[12] J. O. Adewuyi, C. Gwanzura, and D. Mvere, "Characteristics of anti-A and anti-B in black Zimbabweans," Vox Sanguinis, vol. 67, no. 3, pp. 307-309, 1994.

[13] D. G. Saphire, N. S. Rudolph, S. M. Hackleman, and W. H. Stone, "The effect of age on the level of human ABO blood group antibodies," Aging, vol. 5, no. 3, pp. 177-184, 1993.

[14] A. S. David-West, "Blood transfusion and blood bank management in a tropical country," Clinics in Haematology, vol. 10, no. 3, pp. 1013-1028, 1981. 


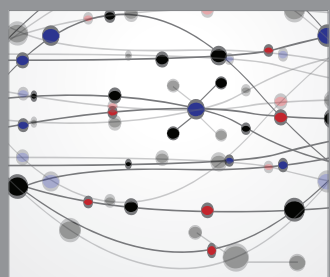

The Scientific World Journal
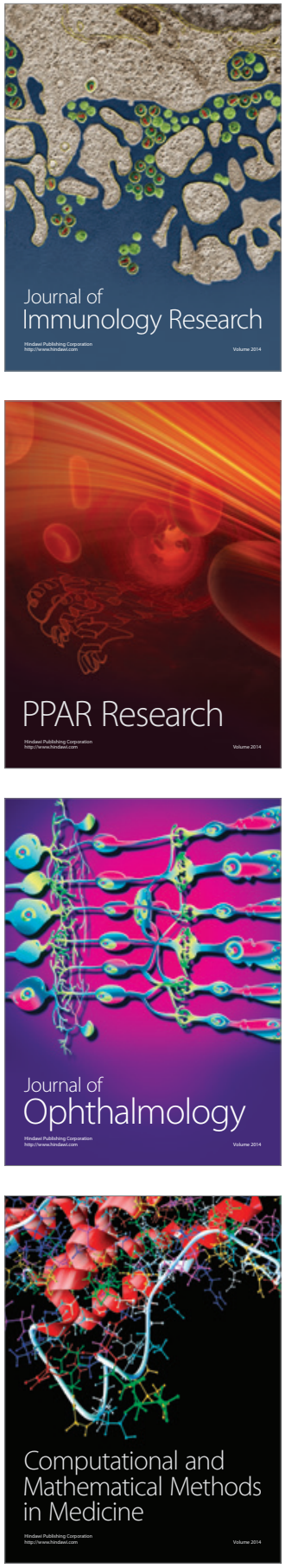

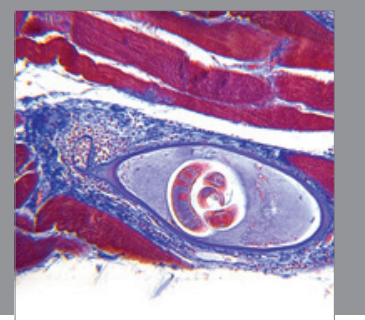

Gastroenterology

Research and Practice
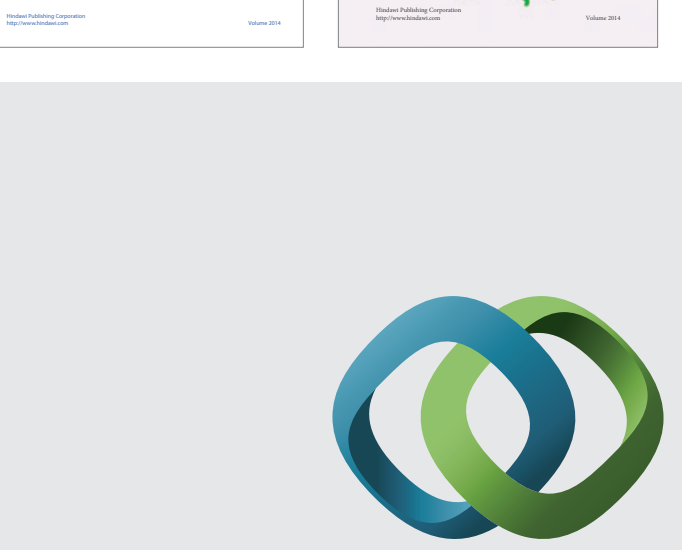

\section{Hindawi}

Submit your manuscripts at

http://www.hindawi.com
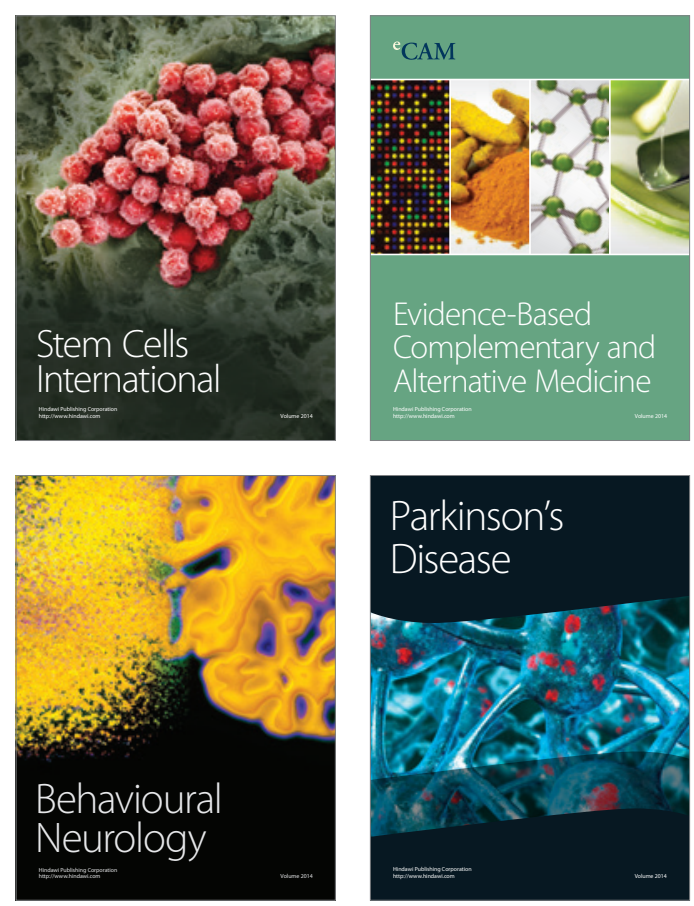

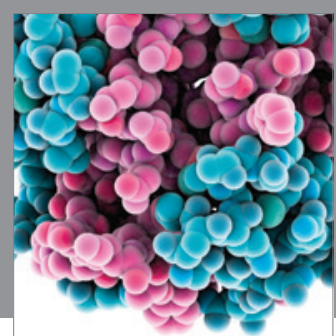

Journal of
Diabetes Research

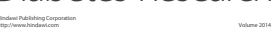

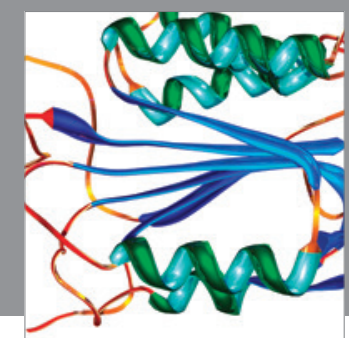

Disease Markers
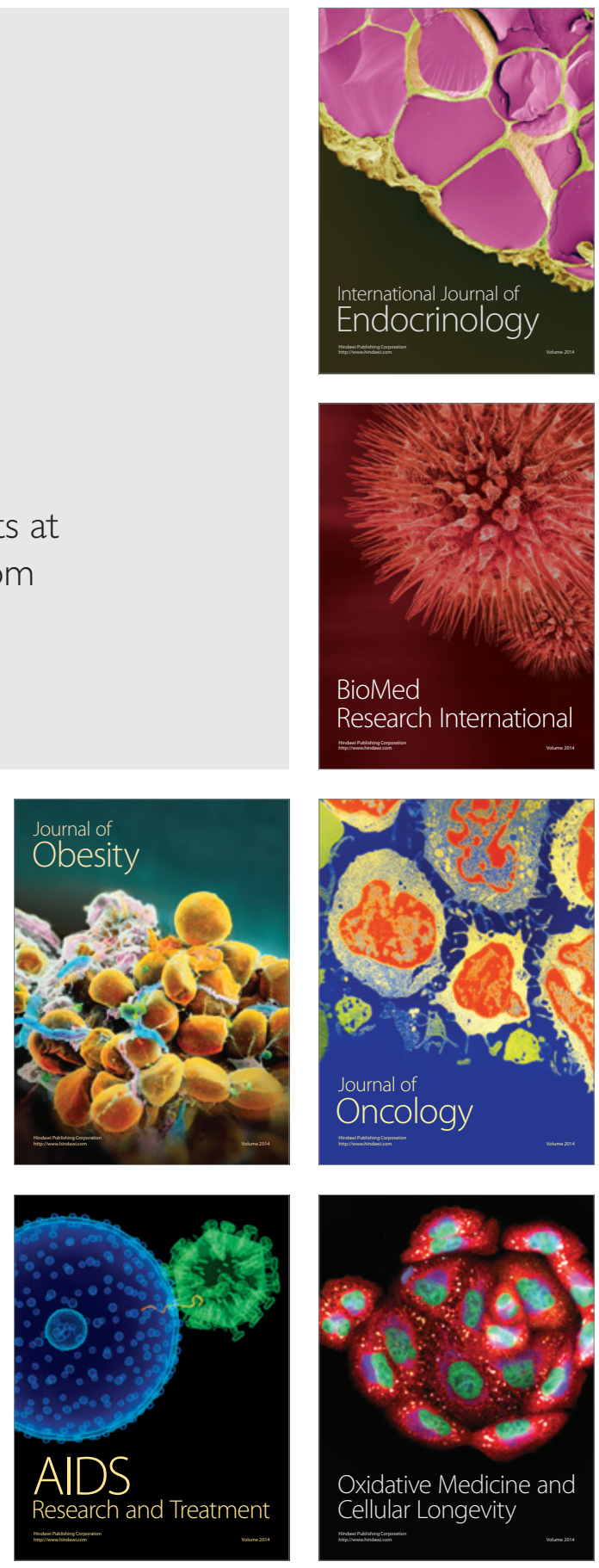